\title{
Molecular identification of allelic genotypes of pyrethroid-insecticide resistance in housefly, Iraq
}

\author{
M.A.A. Alfatlawi ${ }^{1 *}$, M.J. Ali ${ }^{1}$ and H.H. Naser ${ }^{2}$ \\ ${ }^{1}$ Department of Veterinary Microbiology, ${ }^{2}$ Unit of Zoonotic Disease Research, College of Veterinary Medicine, \\ University of Al-Qadisiyah, Al-Diwaniyah, Iraq, *email: monyerr.abd@qu.edu.iq
}

(Received May 29, 2018; Accepted August 14, 2018)

\begin{abstract}
According to global-wide presence of insecticides resistance to pyrethroids, the current study identified the purpose to detect the allelic genotypes regarding this issue in house flies in Iraq. From the governorate of Al-Qadisiyah, Iraq, 60 morphologically and molecularly recognized house flies were caught from 6 different regions. Using a technique called polymerase chain reaction (PCR) amplification of specific allele (PASA), PCR was employed to reveal the presence of allelegenetic variations in the para-type sodium channel (para) gene to recognize knockdown resistance (kdr) mutation from the homozygous-wild type of complete susceptibility (sus/sus) to the mutated-homozygous type of complete resistance $(k d r / k d r)$ or to the mutated-heterozygous type $(k d r / s u s)$. Here, these genotypes were targeted using specific primers to identify these genetic variations. The results have declared the presence of the sus/sus at 100\%-frequency rate in all flies, and none of the other genotypes were detected ( $0 \%)$ in all flies. This valued piece of result indicates the reality of resistance persistence due to lack of insecticide-spraying programs in the governorate. This study provides high-quality information about the current status of insecticide resistance in house flies in Iraq about supporting the fact of genetic-base development of such resistance via frequent use of insecticides.
\end{abstract}

Keywords: Insecticide resistance, $K d r$, Musca domestica.

Available online at http://www.vetmedmosul.com
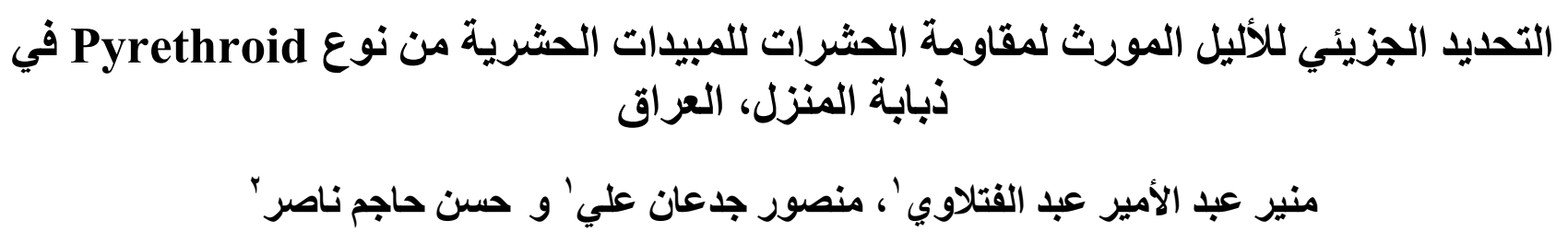

'فرع الأحياء المجهرية البيطرية، وُحدة بحوث الأمر اض المشتركة، كلية الطب البيطري، جامعة القادية، الديو انية، العراق

استناداً للوجود العالمي للمبيدات الحشرية المقاومة للبيرثرويد، حددت الدراسة الحالية الغرض من الكثنف عن الأنماط الجينية الأليلية

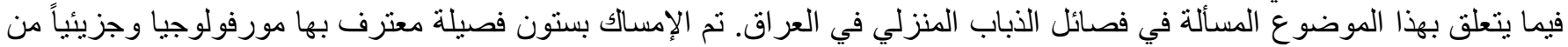

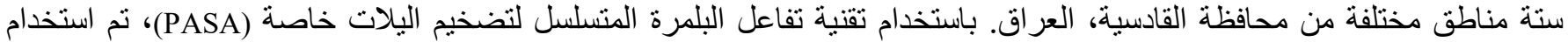

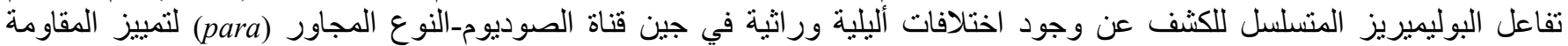

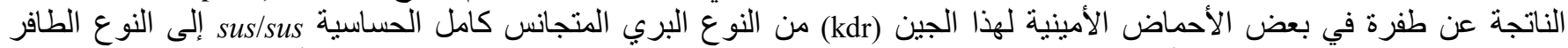

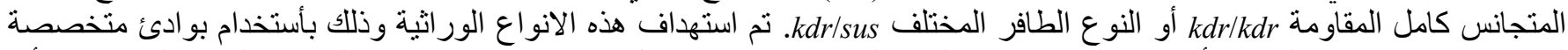

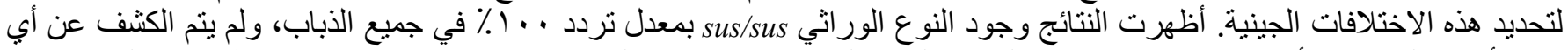

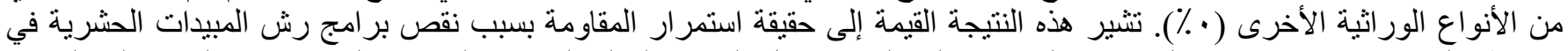

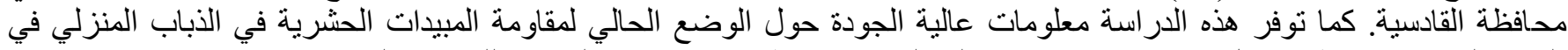

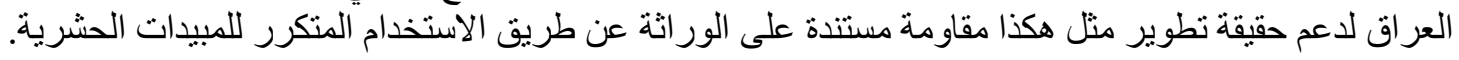




\section{Introduction}

Because insecticides help in reducing the effect of vector-borne diseases, therefore, insecticide-resistance is a dangerous problem that affects environment and its components especially humans, plants, and animals. This problem costs countries around the world about billions of dollars due to the use of not-working chemicals to eradicate insects. This economic-destroying issue could also add dangerous threats to humans, plants, and animals via the persistence and escalating ability of these insects to transmit and store several infectious agents. This ability might induce developing new set of infectious agents that would not be controlled easily (1-4). House flies, Musca domestica, are wide-spread vector that affects human, plants, and animals, and could transfer many fly-borne diseases such as Vibrio cholera, hundreds of fungi, parasites and Escherichia coli O157:H7 (5-9). The problem of resistance by house flies against pyrethroid-based insecticides is increasingly present in the world. The voltage-gated sodium channel $(V s s c)$ plays an important role as a primary target for pyrethroid effect in house flies; however, this target is exposed to certain mutation to insert phenylalanine rather than the original leucine at the residue 1014. This phenylalanine-based replacement is recognized as the $k d r$-gene mutation (10-13). This issue of allelegenotype mutation has been studied in areas of the world but not in Iraq. For this purpose, this study was performed to recognize the knockdown resistance (kdr) mutation from the homozygous-wild type of complete susceptibility (sus/sus) to the mutated-homozygous type of complete resistance $(k d r / k d r)$ or to the mutated-heterozygous type $(\mathrm{kdr} / \mathrm{sus})$ of the para gene in house flies in Iraq.

\section{Materials and methods}

\section{Sampling}

From the governorate of Al-Qadisiyah, Iraq, 60 morphologically and molecularly recognized house flies were caught from 6 different regions. Samples were moved to a laboratory using clean and dry containers.

\section{DNA extraction}

For the purpose of extracting genomic DNA from flies, gSYAN ${ }^{\circledR}$ DNA extraction Kit (Bioneer Company, South Korea) was utilized to perform this process, and the insect protocol of this kit was followed. The quality and quantity of the isolated DNA were measured using NanoDrop spectrophotometer and then were followed by storing the DNA at $-20{ }^{\circ} \mathrm{C}$ to later complete the next step of PASA technique.

\section{PCR amplification of specific allele (PASA)}

The allelic-kdr mutations in the para gene were used to detect the genotypes of pyrethroid resistance in house flies, and the protocol for such analyses was adopted from (14). Two-specific primers of the outer allele, $k d r 1$ : AAGGATCGCTTCAAGG and kdr4: TTCACCCAGTTCTTAAAACGAG, were used to generate a 480bp-piece amplification as a house fly-recognition control. The specific primers for the inner allele, $\mathrm{kdr} 2$ : TCGTGATCGGCAATT and kdr4: TTCACCCAGTTCTTAAAACGAG, were utilized to recognize the kdr-based amplification of a 280 -bp piece. A specific set of primers for the inner allele, kdr1: AAGGATCGCTTCAAGG and kdr3: GTCAACTTACCACAAG, were employed to enhance the sus-based amplification of a $200 \mathrm{bp}$-sized piece. These sets of primers were purchased from Bioneer Company, South Korea.

\section{Preparation of PCR mastermix}

Recruiting the AccuPower ${ }^{\circledR}$ PCR PreMix kit (Bioneer Company, South Korea), PCR mastermix was produced following the company information that was accompanied with the kit. DNA polymerase $1 \mathrm{U}$, dNTPs $250 \mu \mathrm{M}$, Tris$\mathrm{HCl}$ (pH 9.0) $10 \mathrm{mM}, \mathrm{KCl} 30 \mathrm{mM}, \mathrm{MgCl}_{2} 1.5 \mathrm{mM}$, stabilizer, and tracking dye were previously added in the tubes of the kit by the company. The information provided with the kit was followed to perform the mastermix preparation. Adding $2 \mu \mathrm{L}$ of DNA and $1 \mu 110$ pmole from each primer to the above-mentioned tubes was performed, and then the total volume was brought up to $20 \mu 1$. A brief episode of mixing by vortexing was done. The thermocycler conditions were initial denaturation temperature of $94^{\circ} \mathrm{C}$ for $5 \mathrm{~min}, 35$ cycles of the denaturation $94^{\circ} \mathrm{C}$ for $30 \mathrm{~s}$, annealing $54^{\circ} \mathrm{C}$ for $30 \mathrm{~s}$, and extension $72^{\circ} \mathrm{C}$ for $1 \mathrm{~m}$, and final extension at $72^{\circ} \mathrm{C}$ for $5 \mathrm{~m}$. Electrophoresis that recruited a $1 \%$-agarose gel treated with ethidium bromide was performed to then be visualized under a UV illuminator.

\section{Statistical analyses}

The statistics was performed using fraction of total analysis. The results were plotted using GraphPad Prism 7.04 (GraphPad Software Inc., USA).

\section{Results}

According to the PASA results, the study identified the presence of the sus/sus at $100 \%$-frequency rate in all flies, and none of the other genotypes were detected $(0 \%)$ in all flies. These results could be shown and noticed in figure 1 and 2. Figure 1 reveals that the control fragment was amplified at $480 \mathrm{bp}$ in all the samples. Moreover, it shows that the genotype of wild type, sus/sus, has been amplified 
in all the fly samples at $200 \mathrm{bp}$. However, none of the genotypes regarding $k d r / k d r$ or $k d r / s u s$ was amplified in any sample. Figure 2 shows the percentages of these genotypes in the sampled flies.

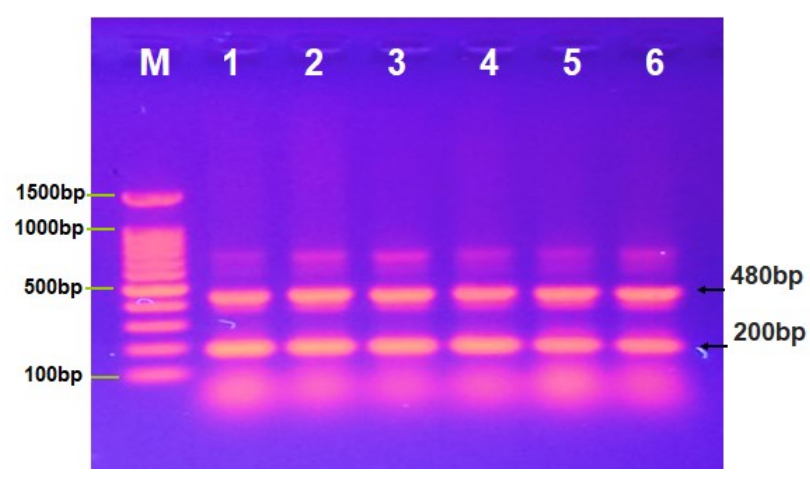

Figure 1: Image of the electrophoresis of the kdr-based genotypes for 6 sampled local locations for the houseflies. Lane $\mathrm{M}$ is the ladder, $1500-100 \mathrm{bp}$. Lanes 1 to 6 are the sampled locations for the houseflies, and they show the amplification of the homozygous-wild type of the para gene (sus/sus) at 200 bp using PASA technique.

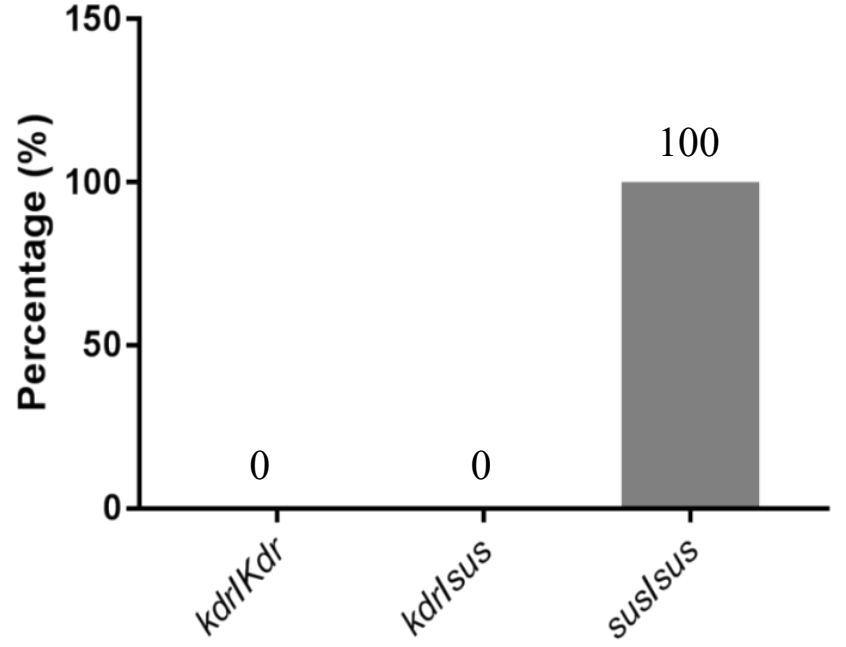

Figure 2: Shows the percentages of the allelic variations of the kdr and the susceptibility to pyrethroid in the sampled flies.

Table 1: Shows the percentages of $k d r / k d r, k d r / s u s$, and sus/sus in some Countries of the world

\begin{tabular}{|c|c|c|c|c|c|c|c|c|c|}
\hline \multirow{2}{*}{ Researcher } & \multirow{2}{*}{$\mathrm{n}$} & \multicolumn{2}{|c|}{$k d r / k d r$} & \multicolumn{2}{|c|}{$k d r / s u s$} & \multicolumn{2}{|c|}{ sus/sus } & \multirow{2}{*}{ Country } & \multirow{2}{*}{ Reference } \\
\hline & & $\mathrm{n}$ & $\%$ & $\mathrm{n}$ & $\%$ & $\mathrm{n}$ & $\%$ & & \\
\hline Our Study & 60 & 0 & 0 & 0 & 0 & 60 & 100 & Iraq & Our \\
\hline WHO & 20 & 0 & 0 & 0 & 0 & 20 & 100 & 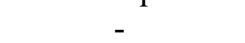 & 15 \\
\hline Huang et al & 743 & 338 & 45.5 & 267 & 36 & 138 & 23.9 & China & 15 \\
\hline Al-Deeb & 122 & 56 & 45.9 & 24 & 19.7 & 48 & 39.3 & United Emirates & 14 \\
\hline
\end{tabular}

$\mathrm{n}=$ number of tested flies.

\section{Discussion}

The current study results showed that all the house flies caught in the regions of the governorate carried the homozygous-wild genotype, sus/sus, and didn't carry any of the genotypes regarding $k d r / k d r$ or $k d r / s u s$. This means that our houseflies have no insecticide resistance based on the disappearance of the mutations, $k d r / k d r$ or $k d r / s u s$. If there is no exposure to insecticides, there is no development of resistance to these chemicals by house flies, and this fact supports our results. Table 1 identifies some studied regions in the world with different ratios of tested allelic variations of the para gene regarding the presence of the $\mathrm{kdr}$ or the sus genotypes $(14,15)$ in which $(15)$ agree with our result of no presence of the kdr-based allelic variations in all of their samples. However, Authors from China (15) indicate that there were $45.5 \%, 36 \%$, and $23.9 \%$ of the $k d r / k d r, k d r / s u s$, and sus/sus respectively. In addition, a researcher from United Emirates (14) detected that ratios of $k d r / k d r$, $k d r / s u s$, and sus/sus were $45.9 \%, 19.7 \%$, and 39.3 respectively. The presence of the $k d r / k d r$ and $k d r / s u s$ genotypes was explained via the frequent use of ineffective insecticides in these countries mentioned in the literature cited above $(14,15)$. Because Iraq has no mass insecticideusing programs by responsible officials or by the local people in the governorate, house flies collected in our study had $0 \%$ presence of the $k d r / k d r$ and/or $k d r / s u s$. This study provides high-quality information about the current status of insecticide resistance in houseflies in Iraq but more globally about supporting the fact of genetic-base development of such resistance via frequent use of insecticides.

\section{References}

1. Ranson H, Lissenden N. Insecticide Resistance in African Anopheles Mosquitoes: A worsening situation that needs urgent action to maintain malaria control. Trends Parasitol. 2016;32(3):187-196. Doi: 10.1016/j.pt.2015.11.010. 
2. Ilias A, Vassiliou VA, Vontas J, Tsagkarakou A. Molecular diagnostics for detecting pyrethroid and abamectin resistance mutations in Tetranychus urticae. Pestic Biochem Physiol. 2017;135:9-14. Doi: 10.1016/j.pestbp.2016.07.004.

3. Kasai S, Sun H, Scott JG. Diversity of knockdown resistance alleles in a single house fly population facilitates adaptation to pyrethroid insecticides. Insect Mol Biol. 2017;26(1):13-24. Doi: org/10.1111/imb.12267.

4. Butler D. Mosquitoes score in chemical war. Nature. 2011;475(7354):19. Doi: 10.1038/475019a.

5. Förster M, Klimpel S, Sievert K. The house fly (Musca domestica) as a potential vector of metazoan parasites caught in a pig-pen in Germany. Vet Parasitol. 2009;160(1-2):163-167. Doi: 10.1016/j.vetpar.2008.10.087.

6. Fotedar R. Vector potential of house flies (Musca domestica) in the transmission of Vibrio cholerae in India. Acta Trop. 2001;78(1):3134. Doi:10.1016/S0001-706X(00)00162.

7. Phoku JZ, Barnard TG, Potgieter N, Dutton MF. Fungi in house fly (Musca domestica L.) as a disease risk indicator: A case study in South Africa. Acta Trop. 2014;140:158-165. Doi:10.1016/j.actatropica.2014.08.019.

8. Ahmad A, Nagaraja TG, Zurek L. Transmission of Escherichia coli O157:H7 to cattle by house flies. Prev Vet Med. 2007;80(1):74-81. Doi:10.1016/j.prevetmed.2007.01.00.

9. Sasaki T, Kobayashi M, Agui N. Epidemiological potential of excretion and regurgitation by Musca domestica (Diptera: Muscidae) in the dissemination of Escherichia coli O157: $\mathrm{H} 7$ to food. J Med Entomol. 2000;37(6):945-949. Doi:10.1603/0022-2585-37.6.945.

10. Elliott M, Janes NF, Potter C. The future of pyrethroids in insect control. Annu Rev Entomol. 1978;23(1):443-469. Doi:10.1146/annurev.en.23.010178.002303.

11. Dong K. Insect sodium channels and insecticide resistance. Invert Neurosci. 2007;7(1):17-30. Doi:10.1007/s10158-006-0036-9.

12. Williamson MS, Martinez-Torres D, Hick CA, Devonshire AL. Identification of mutations in the house fly para-type sodium channel gene associated with knockdown resistance (kdr) to pyrethroid insecticides. Mol Gen Genet. 1996;252(1-2):51-60. Doi.org/10.1007/BF02173204.

13. Miyazaki M, Ohyama K, Dunlap DY, Matsumura F. Cloning and sequencing of the para-type sodium channel gene from susceptible and kdr-resistant German cockroaches (Blattella germanica) and house fly (Musca domestica). Mol Gen Genet. 1996;252(1-2):61-68. Doi:10.1007/BF02173205.

14. Al-Deeb MA. Pyrethroid insecticide resistance kdr gene in the house fly, Musca domestica (Diptera: Muscidae), in the United Arab Emirates. Agric Sci. 2014;05(14):1522-1526. Doi:10.4236/as.2014.514163.

15. Huang J, Kristensen M, Qiao C-L, Jespersen JB. Frequency of kdr gene in house fly field populations: correlation of pyrethroid resistance and kdr frequency. J Econ Entomol. 2004;97(3):1036-1041. Doi:10.1603/0022-0493(2004)097[1036:FOKGIH]2.0.CO;2. 